\title{
ArcheoSciences
}

Revue d'archéométrie

33 (suppl.) | 2009

Mémoire du sol, espace des hommes

\section{Magnetic signal prospecting using multi parameter measurements}

Julien Thiesson, Marie Pétronille and François-Xavier Simon

\section{OpenEdition}

1 Journals

Electronic version

URL: https://journals.openedition.org/archeosciences/1849

DOI: 10.4000/archeosciences. 1849

ISBN: 978-2-7535-1599-4

ISSN: 2104-3728

Publisher

Presses universitaires de Rennes

Printed version

Date of publication: 30 October 2009

Number of pages: $363-365$

ISBN: 978-2-7535-0943-6

ISSN: $1960-1360$

\section{Electronic reference}

Julien Thiesson, Marie Pétronille and François-Xavier Simon, "Magnetic signal prospecting using multi parameter measurements", ArcheoSciences [Online], 33 (suppl.)| 2009, Online since 30 October 2011, connection on 21 September 2021. URL: http://journals.openedition.org/archeosciences/1849 ; DOI: https://doi.org/10.4000/archeosciences.1849 


\title{
Magnetic signal prospecting using multi parameter measurements
}

\author{
Julien Thiesson ${ }^{*, * *}$, Marie PÉTronille ${ }^{*, * * * *}$ and François-Xavier Simon ${ }^{* * *}$
}

Key words: Magnetic susceptibility, Magnetic viscosity, EMI, Magnetic signal, Mapping.

\section{THE MAGNETIC SIGNAL OF SOILS}

The magnetic signal of soils is divided between remanent $(J$,$) and induced magnetization \left(J_{i}\right)$ The former has diverse origins (heating, magnetic viscosity, slow deposition of magnetic bulk in a magnetic field) and is proof of the undisturbed state of features. The other, $J_{i}$, is acquired in the terrestrial magnetic field and is governed by magnetic

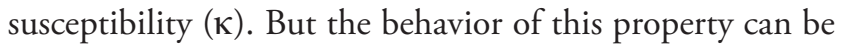
complex when the gain or loss of induced magnetization is decayed. This phenomenon corresponds to negative imaginary in complex $\kappa\left(\kappa=\kappa_{p h}-i \kappa_{q u}\right)$, called magnetic viscosity $\left(\kappa_{\mathrm{qu}}\right)$.

The in-phase magnetic susceptibility, $\kappa_{\mathrm{ph}}$, measurements are mainly sensitive to paramagnetic and ferrimagnetic materials. Beside detection of features, it can be used as a proxy for pedogenesis processes (heavy metal content or bacterial impact). $\kappa_{\mathrm{qu}}$ measurements are only sensitive to ferrimagnetic grains and particularly the near superparamagnetic (SPM)-single-domain (SD) ones.

From these primary measurements we can map derived parameters like the $\frac{\kappa_{q u}}{\kappa_{p h}}$ ratio which indicates the relative part of the magnetic viscous grain in the magnetic signal or the decrease slope map which indicates the spread of mag- netic grain size distribution. With the $\kappa_{p h}$ map, it is possible to evaluate the strength of induced magnetization (Benech et al., 2002). Otherwise, from the $\kappa_{q u}$ map, it is possible to evaluate the strength of the viscous part of remanent magnetization, assuming that grain size distribution is continuous and flat, the decrease slope is, then, near -1 (Thiesson et al., 2007).

Fig. 1 summarizes the magnetic signal of soils and its parts. It also provides parameters that can be mapped. It must be noted that with few hypotheses and the measurements of $\kappa_{p h}, \kappa_{q u}$ and the magnetic field anomaly, it is possible to differentiate $\mathrm{J}_{\mathrm{r}}$ and $\mathrm{J}_{\mathrm{i}}$ and to express the part of $J_{r}$ resulting from viscous remanent magnetization of soil particles.

\section{MeTHODS AND SURVEY}

The Celtic site called 'les Arènes' located at Levroux (Indre, France) was occupied for about a hundred years between the middle of the second century $\mathrm{BC}$ and the middle of the first century BC. Its uniqueness lies in important craft activity aand indeed archaeologists have found pits filled with metallurgical waste (Buchsenschutz et al., 1988). We choose to survey an area called 'terrain Rogier' because of

* UMR 7619 Sisyphe, Université Paris 6 Pierre et Marie Curie, 4 place Jussieu 75252 Paris Cedex 5, France. (julien.thiesson@orleans.inra.fr)

** UR 272 Science du sol, Institut National de Recherche Agronomique, Centre d'Orléans, 2163 avenue de la pomme de pin CS40001 Ardon 45075

Orléans cedex 2, France.

*** Pôle d'Archéologie Interdépartemental Rhénan, Opérations archéologiques, 2, allée Thomas-Edison, ZA sud-CIRSUD 67600 Sélestat, France.

**** Institut de Physique du Globe de Paris, 4 place jussieu 75252 Paris Cedex 5, France. 


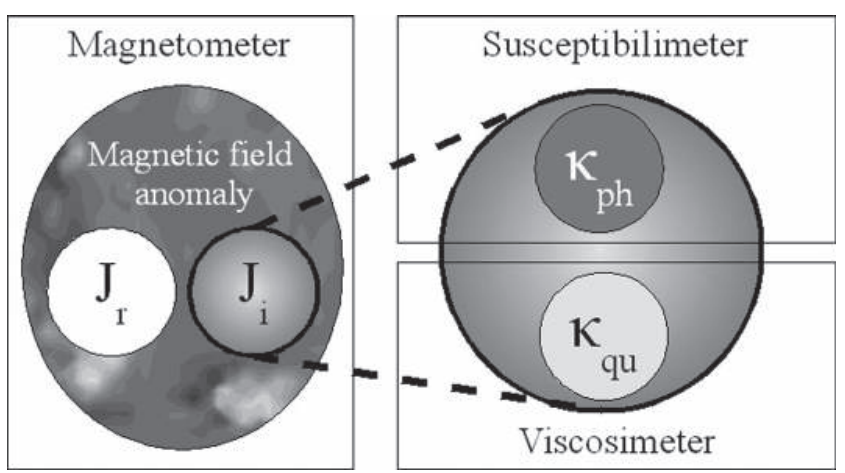

Figure 1: The magnetic signal of soil and how to measure it.

its archaeological and geological characteristics - pits for metallurgical waste were dug in a non-magnetic calcareous substratum, legitimizing therefore the use of both magnetic and electromagnetic methods. A G858 Cesium magnetometer with its two sensors at $0.4 \mathrm{~m}$ above the ground and spaced horizontally $0.6 \mathrm{~m}$ apart, records two parallel profiles simultaneously. The instrument was coupled with a CS60 EMI device (Job et al., 1995). The data were recorded continuously along a profile, then transformed to fit a $1 \times 1 \mathrm{~m}$ grid. The $\kappa_{q u}$ maps were performed using VC100 (Thiesson et al., 2007) with a 1 x $1 \mathrm{~m}$ grid.

\section{RESULTS OF THE PROSPECTION}

Different features can be recognized in the total magnetic field anomaly map (Fig. 2a): compact features with very strong anomaly magnitude and elongated ones with a lower anomaly magnitude. These two types of structures are also observed on the $\kappa_{p h}$ map (Fig. 2b). On the $\kappa_{q u}$ map (Fig. 2c), the compact features can be easily identified but the elongated ones do not appear clearly.

The magnetic anomaly map derived from the CS60 $\kappa_{p b}$, which corresponds to the top-soil induced magnetization anomaly, is clearly lower than the total magnetic field anomaly of the features. This can be the consequences of two facts: either the volume investigated by the CS60 does not contain the whole magnetic feature or the magnetic features have remanent magnetization. Nevertheless, based on the hypothesis that the superficial layer is the most disturbed and does not present any $J_{v}$, we subtracted the CS60 magnetic anomaly map from the total magnetic field anomaly one. The result is a magnetic anomaly map of undisturbed features.

From the value of the $\kappa_{q u}$ it is possible to extrapolate the long term viscous remanent magnetization and to map the
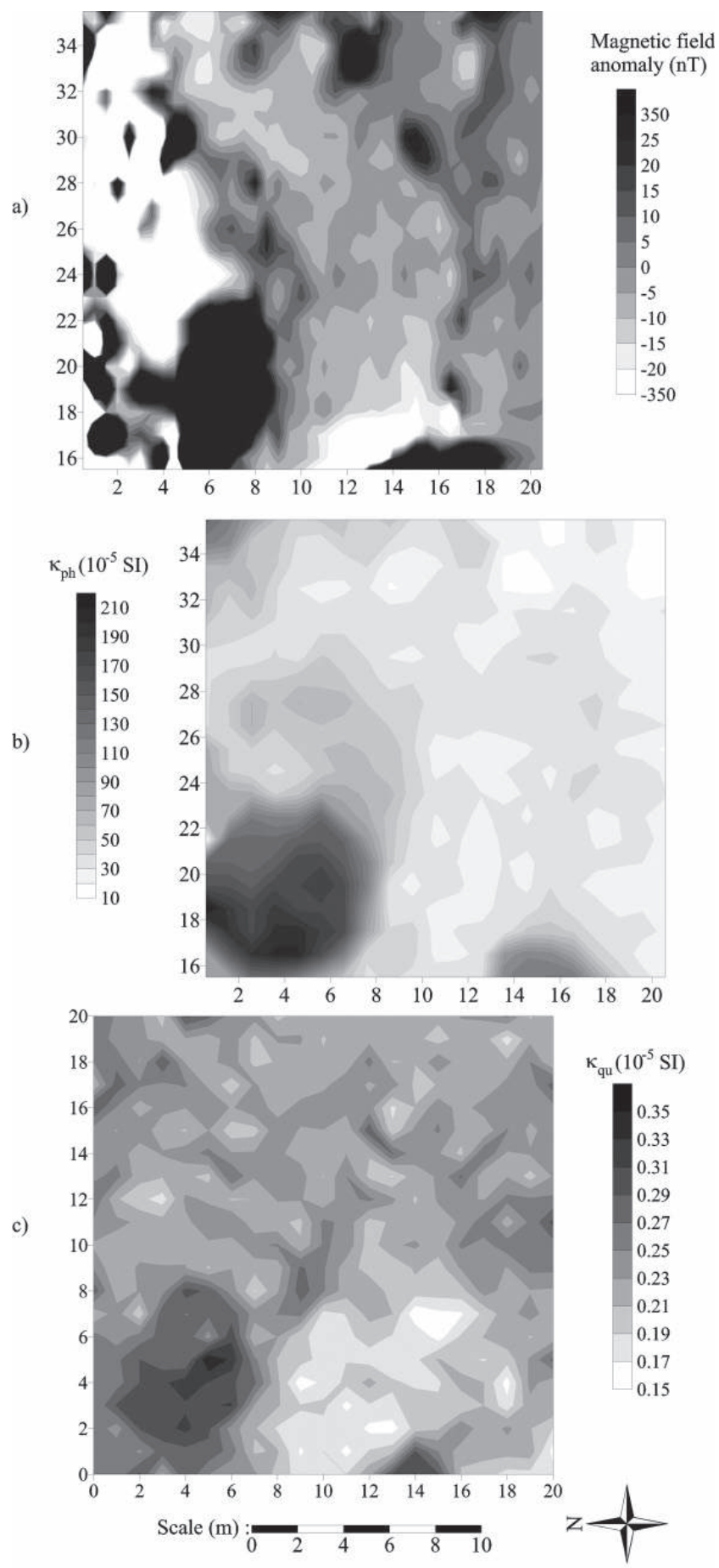

Figure 2: Some maps of magnetic properties: a) Total magnetic field anomaly b) Magnetic susceptibility c) Magnetic viscosity at $44,1 \mu \mathrm{s}$.

magnetic anomalies that are linked to long-term magnetic viscosity. Comparing the relative part of the viscous anomaly to the total magnetic anomaly ensures that we can distin- 
guish features supposed to be linked to metallurgical activities (less viscous) and those more likely to be linked with settlements.

\section{LABORATORY MEASUREMENTS}

A set of samples was taken on both the features identified and a location free of features in order to compare the results from classical laboratory measurements and their interpretation with in situ data. The measurements consisted of:

- hysteresis cycles allowing assessment of grain size distribution;

- thermomagnetic measurements providing information on the nature of magnetic minerals;

- dual-frequency magnetic susceptibility measurements ensuring the evaluation of both $\kappa_{p h}$ and $\kappa_{q u}$ of samples.

The first laboratory results seem to show different features:

- samples taken on some strong magnetic anomalies show a very big magnetic susceptibility $\left(1300.10^{-5} \mathrm{SI}<\kappa<3300.10\right.$ ${ }^{5} \mathrm{SI}$ ) and a very low frequency-dependence susceptibility with $\kappa_{\mathrm{fd}} \%$ of about $1 \%$ at a depth of $0.4 \mathrm{~m}$;

- samples taken on other strong circular magnetic anomalies show a big magnetic susceptibility of 500.10 ${ }^{5} \mathrm{SI}<\mathrm{\kappa}<1000.10^{-5} \mathrm{SI}$ but a high $\kappa_{\mathrm{fd}} \%$ (between $8 \%$ and $10 \%$ ) at a depth of $0.4 \mathrm{~m}$. This indicates the presence of an important quantity of ferrimagnetic grains with sizes on the border between the SPM-SD ones (Dearing et al., 1996);

- the superficial layer of soil and locations without features show lower susceptibility with $150.10^{-5} \mathrm{SI}<\kappa<250.10^{-5}$ SI and $3<\kappa_{\mathrm{fd}} \%<8$.

Therefore, laboratory measurements seem to ensure a differentiation between metallurgical fillings showing small viscosity and other very viscous fillings which will be characterized by micromorphological analysis.

\section{Conclusions}

Three magnetic parameters (magnetic total field anomaly, magnetic susceptibility and magnetic viscosity) have been measured in this survey. These three parameters ensure a better characterization of the magnetic signal of soils. The simultaneous measurement of the total magnetic field and superficial magnetic susceptibility permits an evaluation of the part of the total magnetic field anomaly due to undisturbed features. The evaluation of the viscous part of the total magnetic field anomaly allows us to differentiate the type of the features (linked to metallurgy or to other activities). These results are reinforced by those obtained with classical laboratory measurements which confirm the reliability of the field results in terms of grain sizes distribution, for example.

\section{References}

Benech, C., Tabbagh, A. and Desvignes, G., 2002. Joint inversion of EM and magnetic data for near-surface studies. Geophysics, 67: 1729-1739.

Buchsenschutz, O., Coulon, G., Gratier, M., Hesse, A., Holmgren, J., Mills, N., Orssaud, D., Querrien, A., Rialland, Y., Soyer, C. and TabBagh, A., 1988. L'évolution du canton de Levroux d'après les prospections et les sondages archéologiques, Levroux 1.

Job, J. О., Тавваgh, A. and Наснicha, M., 1995. Détermination par méthode électromagnétique de la concentration en sel d'un sol irrigué. Canadian Journal of Soil Science, 75: 463-469.

Thiesson, J., Tabbagh, A. and Flageul, S., 2007. TDEM magnetic viscosity prospecting using slingram coil configuration. Near Surface Geophysics. 5-6: 363-374. 